\title{
Analisis Pengaruh Revitalisasi Desain Konstruksi Pasar Tradisional Terhadap Peningkatan Pendapatan Asli Daerah (PAD) (Studi Kasus Pasar Glondongan Polokarto Sukoharjo)
}

\author{
Julianto $^{1)}$ \\ 1) Sekretariat Daerah Kabupaten Sukoharjo, Jl. Jend. Sudirman No. 199 Sukoharjo; Telp. 0271-593068. \\ Email: julianto193@yahoo.com
}

\begin{abstract}
Abstrak
Pengembangan pasar memang tidaklah mudah. Revitalisasi pasar memakan biaya yang tinggi. Selain itu di beberapa tempat pengembangan pasar sering dianggap memarginalisasi pedagang lama karena pedagang ditarik retribusi yang lebih besar. Penelitian ini bertujuan untuk mengetahui pengaruh revitalisasi desain konstruksi terhadap peningkatan pendapatan asli Daerah dan menghitung analisa Pendapatan Asli Daerah pada Pasar Glondongan terhadap biaya revitalisasi desain konstruksi Pasar Glondongan. Penelitian ini menggunakan data yang di dapat dari pengelola pasar dan isntansi terkait. Hasil penelitian sebelum dilakukan revitalisasi desain konstruksi pada tahun 2016 memberikan kontribusi pendapatan sebesar 0,0251\% terhadap Pendapatan Asli Daerah. Hal ini bisa di bandingkan dengan kontribusi pendapatan sesudah di revitalisai desain konstruksinya pada tahun 2018 sebesar 0,0256 \% terhadap Pendapatan Asli Daerah. Sehingga sesudah direvitalisasi didapat peningkatan sebesar 0,0005\%. Dengan melihat nilai pendapatan pada tahun 2016 sebesar Rp.63.808.300,00, tahun 2017 sebesar Rp.95.338.400,00 dan tahun 2018 sebesar Rp.111.116.500,00, dapat diambil kesimpulan bahwa pendapatan Pasar Glondongan setelah dilakukan revitalisasi desain konstruksinya terjadi peningkatan.
\end{abstract}

Kata kunci: revitalisasi, pasar, pendapatan.

\begin{abstract}
Development of traditional markets is indeed not easy. Revitalization of the market takes a high cost. Also in some places the development of the market is often considered to marginalize the old traders because the traders are being charged a greater retribution. This study aims to determine the effect of the revitalization of construction design on the increase in regional original income and calculate the analysis of Regional Original Revenue in the Glondongan Market to the cost of revitalizing the construction design of the Glondongan Market. This study uses data obtained from market managers and related institutions. The results of the study prior to revitalizing the construction design in 2016 contributed a revenue of $0.0251 \%$ to the Original Regional Revenue. This can be compared with the contribution of revenue after the construction design revitalization in 2018 of $0.0256 \%$ of the Regional Original Revenue. So that after being revitalized, there was an increase of 0,0005\%. By looking at the revenue value in 2016 amounting to Rp.63,808,300.00, in 2017 amounting to Rp.95,338,400.00 and in 2018 of Rp.111.116,500.00, it can be concluded that an increase in Glondongan Market income after revitalization construction design.
\end{abstract}

Keywords: income, market, revitalization

\section{PENDAHULUAN}

Pasar adalah area tempat jual beli barang dengan jumlah penjual lebih dari satu baik yang disebut sebagai pusat perbelanjaan, pasar tradisional, pertokoan, mall, plasa, pusat perdagangan maupun sebutan lainnya (Peraturan Menteri Perdagangan Republik Indonesia Nomor : 53/M-DAG/PER/12/2008).

Pengembangan pasar memang tidaklah mudah. Revitalisasi pasar memakan biaya yang tinggi. Selain itu di beberapa tempat pengembangan pasar sering dianggap memarginalisasi pedagang lama karena pedagang ditarik retribusi yang lebih besar. Akibatnya bukan peningkatan kesejahteraan yang didapat, bahkan beberapa pedagang lama tersingkir karena tidak sanggup membayar retribusi. Dengan demikian kebijakan ini harusnya mendapat perhatian lebih supaya dapat membuahkan hasil yang maksimal. Karena pasar tradisional adalah salah satu titik tumpu perekonomian masyarakat apabila pengembangannya kurang maksimal maka akan sangat berpengaruh pada kesejahteraan yang berada di lingkungan tersebut, terutama 
para pelaku ekonomi yang berjualan di pasar tersebut.

Pasar tradisional merupakan tempat bertemunya penjual dan pembeli ditandai dengan adanya transaksi atau tawar menawar antara si penjual dan pembeli secara langsung (Rosmawati, Eka. 2015). Menurut (Marlina, Endy. 2008), pola kegiatan pengguna pasar tradisional yang berbeda tergantung pada kelas ekonomi sosial yang ada, latar budaya setempat, usia dan tujuan kedatangannya. Tujuan pengunjung mendatangi pasar tradisional dibedakan menjadi dua, yaitu berbelanja dan berekreasi. arah pendekatan pada kasus studi perilaku ini memandang pasar tradisional sebagai sistem perilaku yang terdiri atas bentuk dari pola kegiatan, pelaku kegiatan dan sifat kegiatan.

Pasar Glondongan Polokarto Sukoharjo terletak pada posisi yang strategis yaitu di pinggir jalan utama penghubung antara kota Sukoharjo dengan Karanganyar. Dengan akses yang mudah dijangkau menjadikan Pasar Glondongan Polokarto Sukoharjo menjadi pilihan utama bagi pembeli yang akan berbelanja dipasar tersebut. Dengan posisi yang strategis tersebut menjadikan Pasar Glondongan Polokarto Sukoharjo jarang sepi dari pengunjung/ pembeli umumnya bagi masyarakat Sukoharjo dan Karanganyar khususnya bagi masyarakat Polokarto.

Pelaksanaan revitalisasi desain konstruksi pasar tradisional merupakan usaha pemerintah agar pasar tradisional mampu bersaing dengan pasar modern. Pembangunan suatu pasar perlu memperhatikan kesejahteraan pedagang maupun pembeli di pasar tersebut. Lewat penataan kembali pasar tradisional yang memperhatikan aspek kenyamanan, pelayanan dan keamanan, maka potensi yang dimiliki pasar tradisional akan dapat meningkatkan perekonomian. Salah satunya adalah pelaksanaan Revitalisasi Desain Pasar Glondongan Polokarto Sukoharjo yang membawa dampak pada kepuasan bagi para pedagang yang berjualan di Pasar Glondongan Polokarto Sukoharjo.

Adapun tujuan dari penelitian ini adalah untuk mengetahui pengaruh revitalisasi desain konstruksi terhadap peningkatan Pendapatan Asli Daerah (PAD) pada Pasar Glondongan Polokarto Sukoharjo. Selain itu juga untuk menghitung analisa Pendapatan Asli Daerah
(PAD) pada Pasar Glondongan Polokarto Sukoharjo terhadap biaya Revitalisasi Desain Konstruksi Pasar Glondongan Polokarto Sukoharjo.

\section{METODE}

\section{Lokasi Penelitian}

Pasar Glondongan Polokarto Sukoharjo terletak pada posisi yang strategis yaitu di pinggir jalan utama penghubung antara kota Sukoharjo dengan Karanganyar yaitu jalan Sukoharjo - Karanganyar atau lebih tepatnya berada di Jl. H. Muslich, Kedunggandu, Wonorejo, Polokarto, Kabupaten Sukoharjo, Jawa Tengah 57555 seperti tampak pada Gambar 1.

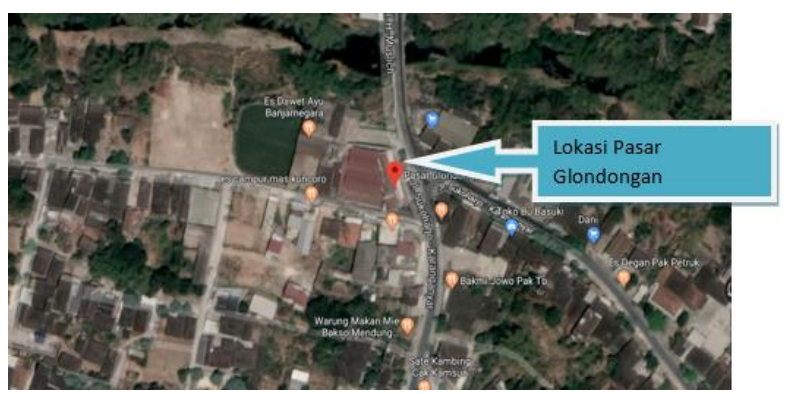

Gambar 1. Lokasi Pasar Glondongan

Dengan akses yang mudah dijangkau menjadikan Pasar Glondongan Polokarto Sukoharjo menjadi pilihan utama bagi pembeli yang akan berbelanja ke pasar. Dengan posisi yang strategis tersebut menjadikan Pasar Glondongan Polokarto Sukoharjo jarang sepi dari pengunjung/ pembeli umumnya bagi masyarakat Sukoharjo dan Karanganyar khususnya bagi masyarakat Polokarto. Pelaksanaan revitalisasi desain konstruksi pasar tradisional merupakan usaha pemerintah agar pasar tradisional mampu bersaing dengan pasar modern.

\section{Metode penelitian}

Penelitian ini menggunakan beberapa tahapan dalam proses pengumpulan data yaitu :

1. Observasi

Melaksanakan pengamatan langsung obyek yang diteliti, dengan cara datang langsung ke lokasi penelitian, dalam hal ini Pasar Glondongan Polokarto Sukoharjo.

2. Wawancara

Wawancara yaitu metode pengumpulan data dengan cara tanya jawab sepihak yang dikerjakan dengan sistematis dan berlandaskan kepada tujuan peneliti. Wawancara yang 
dilakukan dengan wawancara langsung terhadap Petugas Pengelola di Pasar Glondongan Polokarto Sukoharjo.

Dalam penelitian ini, teknik sampling yang digunakan adalah purposive sampling, yaitu teknik pengambilan sampel sumber data dengan pertimbangan tertentu sehingga akan memudahkan peneliti menjelajahi obyek/ situasi sosial yang diteliti. Penentuan sampel dilakukan saat peneliti mulai memasuki lapangan dan selama penelitian berlangsung. Penambahan sampel akan dihentikan ketika datanya sudah jenuh. Maksudnya, dari berbagai informan baik yang lama maupun yang baru, tidak memberikan data baru lagi.

\section{HASIL DAN PEMBAHASAN}

Pasar Glondongan Polokarto Sukoharjo yang telah selesai direvitalisasi desain konstruksinya terdiri dari 2 lantai, lantai 1 diperuntukkan untuk 47 kios, 78 los, $2 \mathrm{KM} / \mathrm{WC}$ dan masih tersedia ruang bagi pegadang oprokan serta tersedia pula lahan parkir yang cukup luas, sedangkan lantai 2 khusus diperuntukkan sebagai kantor pasar. Adapun jenis komoditas barang dagangan antara lain : pakaian, makanan, minuman, sayuran, daging, kelontong, klitikan dan barang-barang kebutuhan pokok lainnya.

Revitalisasi desain konstruksi Pasar Glondongan Polokarto Sukoharjo membutuhkan dana atau biaya yang tidak sedikit, pembanguan pasar ini membutuhkan biaya sebesar Rp.2.403.270.000,00 (Dua milyar empat ratus tiga juta dua ratus tujuh puluh ribu rupiah) dengan sumber dana dari APBD Tahun Anggaran 2017.

Revitalisasi desain konstruksi Pasar Glondongan Polokarto Sukoharjo terdiri dari 2 lantai, pada rancangan denah lantai 1 yang terlihat berupa penataan kios dan los untuk membuat sirkulasi lebih tertata dan nyaman saat berjualan serta layout yang diterapkan untuk merespon udara dari bukaan pintu untuk memecah angin agar terjadi pemerataan dalam ruangan, dan juga terlihat adanya rest area baru pada dalam pasar yang ditujukan untuk tempat peristirahaatan sejenak bagi pengunjung saat berbelanja. Sedangkan lantai 2 khusus diperuntukan sebagai kantor pasar, seperti tampak pada Gambar 2.

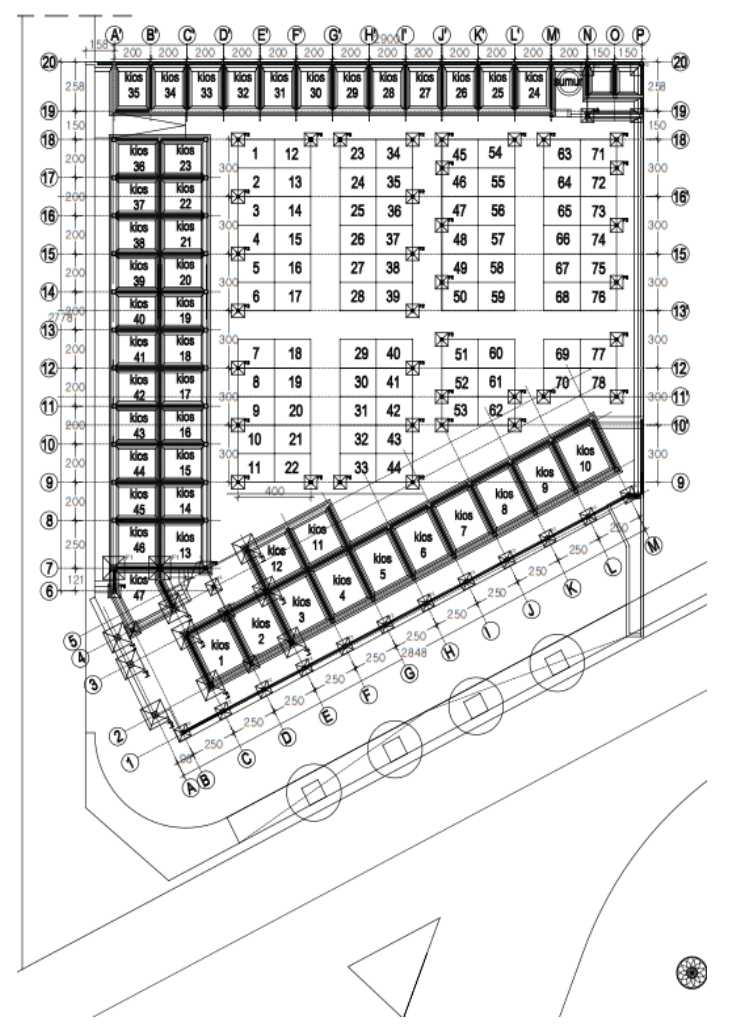

Gambar 2. Denah Lantai 1

\section{Analisis Kontribusi Pendapatan Pasar Glondongan Terhadap Pendapatan Asli Daerah Sukoharjo}

Analisis ini digunakan untuk mengetahui kontribusi dari penerimaan retribusi pasar dalam mendukung Pendapatan Asli Daerah. Analisis ini dilakukan dengan cara membandingkan antara realisasi penerimaan retribusi pasar khususnya Pasar Glondongan Polokarto Sukoharjo dengan total realisasi penerimaan Pendapatan Asli Daerah.

Kontribusi $=($ Realisasi Pendapatan Pasar Glondongan)/(Realisasi Pendapatan Asli Daerah) x $100 \%$

Kontribusi pendapatan Pasar Glondongan tahun 2016.

$$
\begin{aligned}
\text { Kontribusi } & =\frac{63.808 .300,00}{254.164 .870 .016,00} \times 100 \% \% \\
& =0,0251 \%
\end{aligned}
$$

Kontribusi pendapatan Pasar Glondongan Polokarto Sukoharjo tahun 2016 sebesar $0,0251 \%$. Artinya bahwa realisasi pendapatan Pasar Glondongan Polokarto Sukoharjo tahun 2016 memberikan kontribusi dalam realisasi penerimaan Pendapatan Asli Daerah sebesar $0,0251 \%$ dari total realisasi penerimaan Pendapatan Asli Daerah pada tahun 2016. 
Kontribusi pendapatan Pasar Glondongan tahun 2017.

$$
\begin{aligned}
\text { Kontribusi } & =\frac{95.338 .400,00}{464.155 .813 .026,00} \times 100 \% \% \\
& =0,0205 \%
\end{aligned}
$$

Kontribusi pendapatan Pasar Glondongan Polokarto Sukoharjo tahun 2017 sebesar $0,0205 \%$. Artinya bahwa realisasi pendapatan Pasar Glondongan Polokarto Sukoharjo tahun 2017 memberikan kontribusi dalam realisasi penerimaan Pendapatan Asli Daerah sebesar $0,0205 \%$ dari total realisasi penerimaan Pendapatan Asli Daerah pada tahun 2017.

\section{Kontribusi pendapatan Pasar Glondongan} tahun 2018.

$$
\begin{aligned}
\text { Kontribusi } & =\frac{111.116 .500,00}{434.294 .075 .068,00} \times 100 \% \% \\
& =0,0256 \%
\end{aligned}
$$

Kontribusi pendapatan Pasar Glondongan Polokarto Sukoharjo tahun 2018 sebesar $0,0256 \%$. Artinya bahwa realisasi pendapatan Pasar Glondongan Polokarto Sukoharjo tahun 2018 memberikan kontribusi dalam realisasi penerimaan Pendapatan Asli Daerah sebesar $0,0256 \%$ dari total realisasi penerimaan Pendapatan Asli Daerah pada tahun 2018. Dengan melihat nilai pendapatan pada tahun 2016 sebesar Rp.63.808.300,00, tahun 2017 sebesar Rp.95.338.400,00 dan tahun 2018 sebesar Rp.111.116.500,00, dapat diambil kesimpulan bahwa pendapatan Pasar Glondongan Polokarta Sukoharjo setelah dilakukan revitalisasi desain konstruksinya semakin meningkat.

\section{Analisis Payback Period dari Kontribusi Pendapatan Pasar Glondongan Polokarto Sukoharjo}

Peningkatan pendapatan Pasar Glondongan Polokarto Sukoharjo setelah direvitalisasi desain konstruksinya pertahun diambil dari data pendapatan setelah revitalisasi, yaitu tahun 2017, 2018 dan 2019 yang di asumsikan oleh pihak pengelola pasar dengan pendapatan diakhir tahun 2019 sebesar Rp.131.175.500,00. Dengan perhitungan secara lengkap seperti tampak pada Tabel 1. Karena yang diambil adalah data pendapatan setelah direvitalisasi maka yang digunakan data peningkatan pendapatan tahun 2017 dan 2018, setelah dirata-rata didapatkan peningkatan pendapatan pertahun sebesar $17,30 \%$.

Tabel 1. Peningkatan Pendapatan Pertahun.

\begin{tabular}{crcc}
\hline Tahun & Pendapatan (Rp.) & $\begin{array}{c}\text { Peningkatan } \\
\text { Pendapatan } \\
\text { (Rp.) }\end{array}$ & $\begin{array}{c}\text { Peningkatan } \\
\text { Pendapatan } \\
(\%)\end{array}$ \\
\hline 2016 & $63.808 .300,00$ & $31.530 .100,00$ & 49,41 \\
2017 & $95.338 .400,00$ & $15.778 .100,00$ & 16,55 \\
2018 & $111.116 .500,00$ & $20.060 .000,00$ & 18,05 \\
2109 & $131.176 .500,00$ & & \\
\hline
\end{tabular}

Tabel 2. Payback Period dari Pendapatan Pasar Glondongan dengan Asumsi Peningkatan Pertahun $17,30 \%$

\begin{tabular}{ccrccr}
\hline $\begin{array}{c}\text { Tahun } \\
\text { Ke }\end{array}$ & Tahun & Pendapatan/Tahun & $\begin{array}{c}\text { Peningkatan } \\
\text { Pendapatan } \\
\text { Pertahun 17,3\% }\end{array}$ & $\begin{array}{c}\text { Peningkatan } \\
\text { Pendapatan } \\
\text { Pertahun (Rp) }\end{array}$ & $\begin{array}{c}\text { Akumulasi } \\
\text { Pendapatan }\end{array}$ \\
\hline 1 & 2018 & $111.116 .500,00$ & 0,173 & $19.223 .154,50$ & $276.916 .500,00$ \\
2 & 2019 & $130.339 .654,50$ & 0,173 & $22.548 .760,23$ & $407.256 .154,50$ \\
3 & 2020 & $152.888 .414,73$ & 0,173 & $26.449 .695,75$ & $560.144 .569,23$ \\
4 & 2021 & $179.338 .110,48$ & 0,173 & $31.025 .493,11$ & $739.482 .679,71$ \\
5 & 2022 & $210.363 .603,59$ & 0,173 & $36.392 .903,42$ & $949.846 .283,29$ \\
6 & 2023 & $246.756 .507,01$ & 0,173 & $42.688 .875,71$ & $1.196 .602 .790,30$ \\
7 & 2024 & $289.445 .382,72$ & 0,173 & $50.074 .051,21$ & $1.486 .048 .173,03$ \\
8 & 2025 & $339.519 .433,93$ & 0,173 & $58.736 .862,07$ & $1.825 .567 .606,96$ \\
9 & 2026 & $398.256 .296,00$ & 0,173 & $68.898 .339,21$ & $2.223 .823 .902,96$ \\
\hline 10 & 2027 & $467.154 .635,21$ & 0,173 & $80.817 .751,89$ & $2.690 .978 .538,18$ \\
11 & 2028 & $547.972 .387,10$ & 0,173 & $94.799 .222,97$ & $3.238 .950 .925,28$ \\
\hline
\end{tabular}


Berdasarkan Tabel 2 didapatkan bahwa Payback Period revitalisasi desain konstruksi Pasar Glondongan Polokarto Sukoharjo dengan biaya sebesar Rp.2.403.270.000,00 akan kembali pada tahun ke 10 dengan akumulasi pendapatan pada tahun ke 10 sebesar Rp.2.690.978.538,18.

Perhitungan payback period tidak mempertimbangkan nilai suku bunga bank, karena biaya yang dipergunakan dalam revitalisasi konstruksi Pasar Glondongan Polokarto Sukoharjo bersifat tetap yang berasal dari sumber dana APBD TA 2017

\section{SIMPULAN}

Berdasarkan analisis yang telah dilakukan tentang revitalisaisi desain kontruksi di Pasar Glondongan Polokarto Sukoharjo dalam rangka meningkatkan Pendapatan Asli Daerah Kabupaten Sukoharjo, maka dapat ditarik kesimpulan bahwa pendapatan Pasar Glondongan Polokarta Sukoharjo setelah dilakukan revitalisasi desain konstruksinya terjadi peningkatan. Kontribusi Pasar Glondongan terhadap Pendapatan Asli Daerah Kabupaten Sukoharjo juga mengalami peningkatan.

\section{UCAPAN TERIMAKASIH}

Ucapan terima kasih terutama ditujukan Pemkab Sukoharjo atas dukungan dalam penelitian ini.

\section{DAFTAR PUSTAKA}

Kabupaten Sukoharjo. 2011. Peraturan Daerah Kabupaten Sukoharjo Nomor 13 Tahun 2011 tentang Retribusi Daerah. Lembaran Daerah Kabupaten Sukoharjo Tahun 2011 No.13. Sukoharjo : Sekda Kabupaten Sukoharjo.

Kabupaten Sukoharjo. 2017. Peraturan Daerah Kabupaten Sukoharjo Nomor 12 Tahun 2017 tentang Perubahan Atas Peraturan Daerah Kabupaten Sukoharjo Nomor 13 Tahun 2011 tentang Retribusi Daerah. Lembaran Daerah Kabupaten Sukoharjo Tahun 2017 No.12. Sukoharjo : Sekda Kabupaten Sukoharjo.

Kementrian Perdagangan, 2017. Peraturan Menteri Perdagangan Republik Indonesia Nomor : 37/M-DAG/PER/5/2017 tentang Pedoman Pembangunan dan Pengelolaan Sarana Perdagangan. Berita Negara RI
Tahun 2017 No.784. Jakarta : Dirjen Peraturan Perundang-Undangan Kementrian Hukum dan Hak Asasi Manusia RI.

Kementrian Dalam Negeri, 2012. Peraturan Menteri Dalam Negeri Republik Indonesia Nomor 20 Tahun 2012 tentang Pengelolaan dan Pemberdayaan Pasar Tradisional. Berita Negara RI Tahun 2012 No.178. Jakarta : Menteri Hukum dan HAM RI.

Kementrian Perdagangan, 2008. Peraturan Menteri Perdagangan Republik Indonesia Nomor : 53/M-DAG/PER/12/2008 tentang Pedoman Penataan dan Pembinaan Pasar Tradisional, Pusat Perbelanjaan dan Toko Modern.

Kota Yogyakarta. 2009. Peraturan Daerah Kota Yogyakarta Nomor 2 Tahun 2009 tentang Pasar. Lembaran Daerah Kota Yogyakarta Tahun 2009 No.25. Yogyakarta : Sekda Kota Yogyakarta.

Marlina, Endy. 2008. Panduan Perancangan Bangunan Komersial. Yogyakarta : Andi Offset.

Pemerintah Republik Indonesia. 2009. Undang - Undang Republik Indonesia Nomor 28 Tahun 2009 tentang Pajak Daerah dan Retribusi Daerah. Lembaran RI Tahun 2009 No. 130. Jakarta : Sekretariat Negara

Pemerintah Republik Indonesia. 2004. Undang - Undang Republik Indonesia Nomor 33 Tahun 2004 tentang Perimbangan Keuangan Antara Pemerintah Pusat dan Pemerintah Daerah. Lembaran RI Tahun 2004 No.126. Jakarta : Sekretariat Negara.

Pemerintah Republik Indonesia. 2000. Undang - Undang Republik Indonesia Nomor 34 Tahun 2000 tentang Perubahan atas Undang - Undang Republik Indonesia Nomor 18 Tahun 1997 tentang Pajak Daerah dan Retribusi Daerah. Lembaran RI Tahun 2000 No. 246. Jakarta : Sekretariat Negara.

Presiden Republik Indonesia, 2007. Peraturan Presiden Republik Indonesia Nomor 112 Tahun 2007 tentang Penataan dan Pembinaan Pasar Tradisional, Pusat Perbelanjaan dan Toko Modern. 
Presiden Republik Indonesia, 2001, Peraturan Presiden Republik Indonesia Nomor 66 Tahun 2001 tentang Retribusi Daerah, Diundangkan : Jakarta, Lembaran Negara Republik Indonesia Tahun 2001 Nomor 119.

Rosmawati, Eka. 2015. Pengaruh Keberadaan Pasar Tradisional Terhadap Kesejahteraan Pedagang Dampaknya pada Retribusi Pasar (Study Kasus di UPTD Pasar Prapatan, Kec. Sumberjaya, Kab. Majalengka). Fakultas Hukum dan Ekonomi Islam. IAIN Syekh Nurjati Cirebon.ent. 